\title{
Trayectorias de integración social de afromestizos militarizados por las independencias en el Cono Sur. El capitán y preceptor mulato José María Molina (Mendoza/Cuyo, 1803-1863)
}

Social integration trajectories of Afromestizos militarized by independence in the Southern Cone. The captain and mulatto preceptor José María Molina (Mendoza / Cuyo, 1803-1863)

Orlando Gabriel Morales Instituto de Ciencias Humanas, Sociales y Ambientales, Mendoza

Luis César Caballero

Centro de Genealogía y Heráldica de San Juan

DOI: https://doi.org/10.25032/crh.v5i9.3

Recibido: 2/10/2019

Aceptado: 26/11/2019

Resumen. El artículo reconstruye y contextualiza la trayectoria social del afromestizo José María Molina (1803-1863) y su familia en Mendoza/Cuyo durante el siglo XIX. Molina se incorporó al Cuerpo de Cívicos Pardos de Mendoza durante la campaña libertadora sanmartiniana y trascendió en la opinión pública en 1835 por su complicidad con el coronel pardo Lorenzo Barcala en una conspiración frustrada de los unitarios para reemplazar el gobierno de Mendoza y debilitar la influencia política de Juan Manuel de Rosas en las provincias del Río de la Plata. La trayectoria de Molina, con similitudes a la de otros afromestizos militarizados a ambos lados de los Andes Sur durante las independencias nacionales, deja ver en el largo plazo un proceso de integración social con estrategias de movilidad, solidaridades intragrupales y agenciamiento político.

Palabras clave: Cuyo/Mendoza, afromestizos, militarización, integración social.

Abstract. This article reconstructs and contextualizes the social trajectory of the afromestizo José María Molina (1803-1863) and his family in Mendoza / Cuyo during the 19th century. Molina joined the Cuerpo de Cívicos Pardos de Mendoza during the Sanmartinian liberation campaign and transcended public opinion in 1835 for his 
complicity with Colonel Lorenzo Barcala in a frustrated conspiracy of the Unitarians to replace the Mendoza government and weaken political influence Juan Manuel de Rosas in the provinces of the Río de la Plata. Molina's trajectory, similar to that of other militarized afromestizos on both sides of the South Andes during national independence, reveals in the long term a process of social integration with mobility strategies, intra-group solidarity and political agency.

Keywords: Mendoza/Cuyo, Afromestizos, militarization, social integration.

\section{Introducción}

Este artículo ${ }^{1}$ retoma y amplía un estudio biográfico anterior que reconstruyó parcialmente la vida del mulato José María Molina (Mendoza, 1803-1863). ${ }^{2}$ Molina nació esclavo y obtuvo la libertad a corta edad por manumisión voluntaria del propietario, se desempeñó en el oficio de sastre, aprendió a leer y escribir, se alistó como miliciano cívico, como tal fue protagonista de acontecimientos políticos relevantes en la provincia de Mendoza, constituyó un matrimonio y una familia con hijos legítimos e ilegítimos, fue cófrade de Nuestra Señora de la Merced y se desempeñó como preceptor en una escuela de primeras letras. La restitución de la trayectoria social de Molina y su familia, con una mirada de largo plazo que abarca buena parte el siglo XIX, tiene por objeto explorar diferentes aspectos del proceso de integración social que protagonizaron los afromestizos, esclavos y libres, en Cuyo3 a fines del período colonial y especialmente después de la revolución de 1810 en el Río de la Plata. Se focaliza en la experiencia social y política de José María a partir de su

\footnotetext{
${ }^{1}$ Este trabajo fue financiado a través del PICT 2017-3306, «Esclavitud, emancipación y ciudadanía en el Río De La Plata. Estudio comparado de africanos y afrodescendientes en Buenos Aires, el Litoral, Cuyo y Córdoba (1776-1860)», Agencia Nacional de Promoción Científica y Tecnológica.

${ }^{2}$ La biografía de José María Molina fue reconstruida parcialmente en una ponencia presentada en las VI Jornadas del Grupo de Estudios Afrolatinoamericanos. En este artículo se amplían sustancialmente la información biográfica, la contextualización y los argumentos.

3 La ciudad de Mendoza fue fundada por los colonizadores españoles en 1561 y poco tiempo después se fundaron las ciudades de San Juan de la Frontera (1562) y San Luis de Loyola (1594). Las tres ciudades comprendieron el Corregimiento de Cuyo - también conocido como provincia de Cuyo- integrado a la Capitanía General de Chile, dependiente del Virreinato del Perú, hasta la creación del Virreinato del Río de la Plata en 1776. En 1784 el Corregimiento fue subsumido en la Intendencia de Córdoba del Tucumán, hasta la creación de la Intendencia de Cuyo en 1813, con capital en Mendoza. En 1820 se disolvió la Intendencia en las provincias autónomas de Mendoza, San Juan y San Luis, cuyas ciudades capitales son homónimas a cada provincia.
} 
inserción en la milicia cívica, pero el análisis a microescala comprende a su familia y permite identificar experiencias y saberes compartidos, estrategias de movilidad a nivel familiar, solidaridades intragrupales y cambios en las prácticas de alterización/identificación social en el largo plazo.

El estudio recurre a un análisis cualitativo intensivo de fuentes archivísticas heterogéneas y fuentes primarias publicadas que registran algunos acontecimientos biográficos de José María Molina y de integrantes de su familia y su entorno social. Los distintos documentos analizados (protocolos notariales, expedientes judiciales, libros parroquiales, correspondencia de gobierno, listas militares) se alojan en el Archivo Nacional Histórico de Chile (ANH), el Archivo General de la Nación (AGN, Argentina), el Archivo General de la Provincia de Mendoza (AGPM) y el Archivo del Arzobispado de Mendoza (ARZ).

Aunque permanecieron sin atraer la atención de los historiadores durante mucho tiempo, algunos milicianos mulatos que lograron altos rangos militares o que se destacaron por su educación y ejercicio como letrados dejaron, por las características de sus trayectorias, un registro documental considerable que ahora posibilita estudios biográficos bien documentados. En cambio, el análisis de la vida de un personaje mulato corriente como José María Molina no se puede realizar sin un intenso trabajo de archivo para reunir informaciones muy dispersas y fragmentarias. Molina adquirió notoriedad pública en 1835 cuando fue hallado culpable de complicidad en un plan conspirativo que tramaba el prestigioso coronel pardo Lorenzo Barcala, identificado con el unitarismo, contra el gobierno de la provincia de Mendoza y la influencia política de Juan Manuel de Rosas en la región. Sin embargo, la historiografía nunca le prestó atención y no lo mencionó más que de modo secundario, con un enfoque centrado en el célebre personaje Barcala y en su excepcionalidad como militar destacado en el unitarismo. Molina no adquirió la notoriedad militar de su contemporáneo el coronel Barcala, no se elevó de esclavo a líder militar y político como el afrouruguayo Jaime Feliciano González, (Borucki 2017 276-281), ni recibió una educación de elite como el letrado negro de Montevideo Jacinto Ventura de Molina (229-266). El capitán mendocino en cuestión tampoco tuvo el honor de comandar la milicia o de recibir una medalla de oro como el mulato chileno Gregorio José de Arenas (Contreras 2011 58-62). Pese a todo, esa no excepcionalidad que acerca a Molina a un afromestizo corriente tiene singular valor a los fines de nuestro estudio. 
La atención sobre un miliciano mulato y en particular en el capitán José María Molina se explica por dos motivos relacionados entre sí. Por una parte, con anterioridad en nuestras investigaciones exploramos genealogías de esclavos, (Caballero, 2010), prácticas de marcación social de alteridad, dinámicas de identificación y estrategias de movilidad de africanos y afromestizos militarizados en Mendoza y Cuyo durante las guerras de independencia en el Río de la Plata. 4 Por otra, en ese proceso de trabajo restituimos la biografía del coronel Lorenzo Barcala, 5 quien inició su carrera militar en el Cuerpo de Cívicos Pardos de Mendoza y se destacó en las armas hasta su fusilamiento por su responsabilidad en la mencionada conspiración del año 1835. Fue en el marco del estudio biográfico de Barcala que identificamos la trayectoria social de Molina. Las biografías individuales de oficiales mulatos permiten contrastar nuestra hipótesis de que la militarización favoreció la integración y movilidad social de los negros y mulatos y sus familias en el pasaje de la sociedad colonial a la independiente.

La historiografía hispanoamericana logró en las últimas décadas importantes avances en el conocimiento de las prácticas sociales y políticas de los negros y mulatos apoyadas en la participación en cuerpos armados al servicio de la corona española y, más tarde, en los ejércitos de línea y las milicias nacionales. Algunas problemáticas, como el acceso a la ciudadanía, la adquisición de preeminencias sociales, la incorporación a la política y la construcción de legitimidad y prestigio social, con base en la carrera en las armas, ahora son mejor conocidas para distintas regiones. ${ }^{6} \mathrm{El}$

4 Orlando Gabriel Morales, «Identificaciones de los plebeyos de color militarizados durante la revolución de la independencia en el Río de la Plata. Cuyo 1810-1816». Estudios Sociales, n. ${ }^{\circ}$ 53, 2017, pp. 127-154; Orlando Gabriel Morales y Luis César Caballero. «Movilidad social de afromestizos movilizados por la independencia y las guerras civiles en el Río de la Plata. Lorenzo Barcala (1795-1835)». Historia y Memoria, vol. 16, 2018, pp. 106-107.

5 Morales y Caballero, «Movilidad social de afromestizos movilizados...» y «Lorenzo Barcala: "Esclavo", "hijo de la revolución" y "civilizador de masas" Una discusión de las mitificaciones historiográficas de los afroargentinos». Tiempo Histórico, vol. 9, n. ${ }^{0}$ 16, 2018, pp. 39-59.

${ }^{6}$ Véanse por ejemplo los trabajos de George Reid Andrews, Los afroargentinos de Buenos Aires. Buenos Aires: Ediciones de la Flor, 1989, pp. 137-165; Alfonso Múnera, El fracaso de la nación. Región, clase y raza en el Caribe colombiano (1717-1821). Bogotá: Banco de la República-El Áncora, 1998, pp. 173-215; Ben Vinson III, «Los milicianos Pardos y la construcción de la raza en el México colonia», Signos históricos, vol. 2, n. ${ }^{\circ}$ 4, 2000, pp. 87-106; Gabriel Di Meglio, «Las palabras de Manul. La plebe porteña y la política en los años revolucionarios» ¿Y el pueblo dónde está? Contribuciones para una historia popular de la Revolución de Independencia en el Río de la Plata. ed. Raúl O. Fradkin. Buenos Aires: Prometeo, 2009, pp. 107-150; Hugo Contreras Cruces, «Las milicias de pardos y morenos libres de Santiago de Chile en el siglo XVIII, 1760-1800», Cuadernos de Historia, vol. 25, 2006, pp. 93-117; «Artesanos mulatos y soldados beneméritos. El Batallón de Infantes de la Patria en la Guerra de Independencia de Chile. 1795-1820", Historia, vol. 1, n. ${ }^{\circ}$ 44, 2011, pp. 51-89; «Ser leales y parecer «decentes». Milicias de castas e inserción social de los afrodescendientes. Chile, 1675-1760», Tiempo 
bicentenario de las independencias nacionales se constituyó en una oportunidad para que los historiadores coincidieran en la importancia de revisar la participación de los sectores populares, y en particular de los esclavos y los africanos y afrodescendientes libres, en los procesos independentistas hispanoamericanos.7

Para el caso de Argentina, en la década del ochenta Andrews planteó el problema del escaso conocimiento del rol de los afroargentinos en las guerras y con una lectura crítica de la historiografía tradicional dejó el camino abierto a nuevas preguntas, por ejemplo respecto del acceso a la oficialidad de los soldados afroargentinos y su agenciamiento para elevarse a altos niveles de mando. ${ }^{8}$ Después de la obra pionera de Andrews, la historiografía que asumió la agencia de los africanos y sus descendientes y centró el análisis en sus prácticas sociales y políticas comenzó a pensar los cuerpos armados como espacios de sociabilidad y plataforma de estrategias multisituadas de movilidad social ascendente.

En esa línea de estudios, con centro fundamentalmente en Buenos Aires y Montevideo, en las últimas cuatro décadas se amplió el conocimiento de diversos ámbitos de socialización de la población negra rioplatense durante la colonia y en las primeras décadas del siglo XIX, tales como las cofradías de negros, las asociaciones o naciones africanas, las milicias de negros libres, y los vínculos y superposiciones entre

Histórico, vol. 8, n. ${ }^{\circ}$ 14, 2017, pp. 129-155; Alex Borucki, De compañeros de barco a camaradas de armas. Identidades negras en el Río de la Plata, 1760-1860, Buenos Aires: Prometeo, 2017, pp. 111-185. 7 En el caso del Río de la Plata son representativos los trabajos reunidos por Silvia C. Mallo e Ignacio Telesca, «Negros de la patria». Los afrodescendientes en las luchas por la independencia en el antiguo Virreinato del Río de La Plata, Buenos Aires: SB, 2010. También los trabajos de Carmen Bernand, «Los olvidados de la revolución: el Rio de la Plata y sus negros», Nuevo Mundo Mundos Nuevos [En ligne] Colloques, 2010. Recuperado a partir de http://journals.openedition.org/nuevomundo/58416, Florencia Guzmán, «Afroargentinos, guerra y política, durante las primeras décadas del siglo XIX. Una aproximación hacia una historia social de la revolución», Estudios Históricos, vol. 11, 2013, pp. 1-24. En la región andina se hizo lo propio en la obra de Heraclio Bonilla, Indios, negros y mestizos en la independencia. Bogotá: Planeta Colombiana-Universidad Nacional de Colombia, 2010.

8 George Reid Andrews, Los afroargentinos de Buenos Aires. Buenos Aires: Ediciones de la Flor, 1989, pp. 137-165. La primera edición de esta obra de Andrews se publicó en inglés en 1980, y la edición en español se editó en 1989. Antes el autor había publicado un trabajo que revisaba la composición racial y organización de cuerpos de soldados negros, milicias y ejércitos de línea, y sus cambios en el tiempo durante la primera mitad del siglo XIX en la provincia de Buenos Aires. Véase George Reid Andrews, «The Afro-Argentine Officers of Buenos Aires Province, 1800-1860», The Journal of Negro History, vol. $64,{ }^{\circ}{ }^{2}, 1979$, pp. 85-100. 
estas instituciones a partir de las prácticas de los actores en el proceso de construir identidades, liderazgos y prestigio y movilidad social. 9

Del otro lado de los Andes, en un territorio y espacio social que fue cercano para la población negra cuyana, los estudios históricos recientes de los africanos y afrodescendientes han registrado procesos sociales similares. Durante el período colonial y buena parte del siglo XIX la sociedad cuyana tuvo fuertes vínculos con la trasandina por la circulación de población en una jurisdicción de la Capitanía General de Chile y por estrechos lazos comerciales, culturales y políticos que tuvieron un hito singular en la coyuntura específica de la retirada hacia Mendoza de los patriotas chilenos después de la derrota de Rancagua y del reclutamiento de los esclavos, libertos y milicianos mulatos emigrados para la formación del Ejército de los Andes, que emprendió en 1817 la campaña libertadora de Chile. Los trabajos de Contreras Cruces sobre las compañías de castas libres al servicio de la corona española y especialmente sobre el caso de Batallón de Infantes de la Patria, durante la guerra de independencia de Chile, muestran que los artesanos mulatos apelaron a su participación en esos cuerpos para construir prestigio social y esa destacada institución les permitió catalizar otras experiencias de sociabilidad. ${ }^{10}$

\footnotetext{
9 La producción historiográfica sobre los africanos esclavizados y sus descendientes en el Río de la Plata durante la colonia y el siglo XIX es amplia y se ha multiplicado en los últimos años, pero por una cuestión de espacio y de relación con la problemática de estudio en este artículo acotamos su referencia a aquellos trabajos cuyos aportes permiten apreciar las experiencias de integración social de la población negra en el pasaje de la sociedad colonial a la independiente. Además de los mencionados George Reid Andrews, Los afroargentinos, y Alex Borucki, De compañeros de barco; véanse los trabajos de Silvia Mallo, «La libertad en el discurso del Estado, de amos y esclavos, 1780-1830», Revista de Historia de América 112 (1991): 121-146; Ana Fraga, «Caminos de libertad en tiempos de revolución. Los esclavos en la Provincia Oriental Artiguista, 1815-1820». Estudios sobre la cultura afro-rioplatense. Historia y presente. comp. Arturo Bentancur, Alex Borucki y Ana Fraga (Montevideo: FHCE, 2004). 45-66; Oscar Chamosa, «To Honor the Ashes of Their Forebears»: The Rise and Crisis of African Nations in the Post-Independence State of Buenos Aires, 1820-1860", The Americas 59.3 (2004): 347-378; Miguel Ángel Rosal, Africanos y afrodescendientes en el Río de La Plata. Siglos XVIII-XIX (Buenos Aires: Dunken, 2009); Marta Beatriz Goldberg, «Afrosoldados de Buenos Aires en armas para defender a sus amos». «Negros de la patria». Los afrodescendientes en las luchas por la independencia en el antiguo Virreinato del Río de La Plata. eds., Silvia C. Mallo e Ignacio Telesca (Buenos Aires: SB, 2010). 39-63; Alex Borucki, Karla Chagas y Natalia Stalla, «Abolición y esclavitud en el Estado Oriental del Uruguay, 1830-1860». «Negros de la patria». Los afrodescendientes en las luchas por la independencia en el antiguo Virreinato del Río de La Plata. eds., Silvia C. Mallo e Ignacio Telesca (Buenos Aires: SB, 2010). 211-228; Liliana Crespi, «Esclavos, libres y libertos del Río de la Plata. Un lento acceso a la ciudadanía». La Ruta del Esclavo en el Río de la Plata. Aportes para el diálogo intercultural. comp. Marisa Pineau (Buenos Aires: UNTREF, 2011). 187-202; Florencia Guzmán, «De esclavizados a afrodescendientes. Un análisis histórico sobre la movilidad social a finales de la colonia», Boletin Americanista LXI 2.63 (2011): 13-34; Magdalena Candioti, «Abolición gradual y libertades vigiladas en el Río de la Plata. La política de control de libertos de 1813», Corpus [en línea] 6.1 (2016). URL: http://corpusarchivos.revues.org/1567
}

10 Nos referimos a los siguientes trabajos de Hugo Contreras Cruces, «Las milicias de pardos y morenos libres de Santiago de Chile en el siglo xviii, 1760-1800». Cuadernos de Historia, vol. 25, 2006, pp. 93- 
La historiografía cuyana, en particular, no ha puesto atención en la historia social de los africanos esclavizados y sus descendientes en Cuyo. Masini Calderón realizó los primeros estudios que permitieron conocer las características de la esclavitud y de la incorporación de esclavos en los ejércitos patrios durante el período independiente en Cuyo, con aportes sobre el régimen jurídico de la esclavitud en la Hispanoamérica colonial (Régimen jurídico), la evolución de esa institución en el Río de la Plata a partir de la revolución de 1810 (La esclavitud negra en la República), algunas características de la esclavitud en las tres provincias de Cuyo en el período independiente (La esclavitud negra en San Juan), el dispositivo administrativo y normativo del reclutamiento militar de esclavos para el Ejército de los Andes y otros cuerpos armados (La esclavitud negra en Mendoza). Las evidencias que entregó Masini Calderón en la década del sesenta sobre la relevancia cuantitativa de los libertos y el impacto de la extracción de esclavos para las armas dio lugar a que cinco décadas después, desde una historiografía renovada, Bragoni planteara la pregunta por los procesos de politización y oportunidades sociales abiertas a los sectores populares a partir de la militarización vinculada al proyecto libertador sanmartiniano con base en Mendoza desde $1814 .{ }^{11}$

En dialogo con los aportes reseñados, esta reconstrucción de la trayectoria social del capitán José María Molina comienza por una restitución de la configuración de su familia de origen, de sus experiencias de manumisión y agenciamiento como sujetos de derecho, de la constitución de una nueva familia por José María, y de las prácticas de alterización/identificación social de los miembros de la familia en perspectiva intergeneracional y en el largo plazo. Luego se describe la trayectoria de José María Molina en la milicia cívica de Mendoza, con atención a su participación, antes y después de su retiro del servicio activo, en acciones con repercusiones políticas y

117; «Artesanos mulatos y soldados beneméritos. El Batallón de Infantes de la Patria en la Guerra de Independencia de Chile. 1795-1820». Historia, vol. 1, n. ${ }^{\circ}$ 44, 2011, pp. 51-89; «Ser leales y parecer «decentes». Milicias de castas e inserción social de los afrodescendientes. Chile, 1675-1760». Tiempo Histórico, vol. 8, n. ${ }^{0}$ 14, 2017, pp. 129-155.

${ }^{11}$ La relación entre militarización y participación política de los sectores populares durante la guerra de independencia en el Río de la Plata se convirtió en un tema importante de la reflexión historiográfica en las últimas décadas, véase Gabriel Di Meglio, iViva el bajo pueblo!; Raúl O. Fradkin, ¿Y el pueblo dónde está?. Contribuciones para una historia popular de la Revolución de Independencia en el Río de la Plata. Buenos Aires: Prometeo, 2009; Raúl O. Fradkin y Gabriel Di Meglio, Hacer política. La participación popular en el siglo XIX rioplatense. Buenos Aires: Prometeo, 2013; Ariel de la Fuente, Los hijos de Facundo. Caudillos y montoneras en la provincia de la Rioja durante el proceso de formación del Estado nacional argentino (1853-1870). Buenos Aires: Prometeo, 2014. 
especialmente en la conspiración de 1835 contra el gobierno de la provincia de Mendoza. Finalmente y para cerrar el artículo exponemos una síntesis conclusiva que recupera las ideas centrales del trabajo.

\section{Familia}

\section{Esclavitud y manumisión}

Molina fue bautizado en la ciudad de Mendoza el 11 de setiembre de 1803, dos días después de su nacimiento, como José María, mulato, hijo de padre no conocido y esclavo de don Felipe Molina. ${ }^{12}$ Su madre se llamaba Jacinta, hija de Casimira, ambas eran esclavas del mencionado Felipe, quien las compró el 16 de diciembre de 1787 en Mendoza a Don Fernando Garay por la suma total de cuatrocientos pesos. ${ }^{13} \mathrm{El}$ cambio de propietario implicó que Casimira y Jacinta recibieran un nuevo apellido, por eso en la reconstrucción de la genealogía de José María Molina (Figura 1) se puede apreciar el cambio de apellido de ambas mujeres.

12 Archivo del Arzobispado de Mendoza (ARz), Mendoza, Libros de Bautismos, Parroquia Matriz, Libro 11 Bis, Castas, Años 1799/1807, f. 83.

13 Escribano Pedro Pablo de Videla, años 1783/1788. Archivo General de la Provincia de Mendoza (AGPM), Mendoza, Protocolo 114, 16 de diciembre de 1787, f, 157v-158. 
Figura 1. Genealogía de José María Molina

\begin{tabular}{|c|c|}
\hline Bisabuela $\rightarrow$ & $\begin{array}{l}\text { Pascuala Garay } \\
\text { Natural de Córdoba, Argentina. } \\
\text { Esclava de Don Francisco Garay } \\
\downarrow\end{array}$ \\
\hline Abuela & $\begin{array}{l}\text { María Casimira (Garay) Molina José Ramón Galván } \\
\text { n.3/3/1762 Córdoba Indio-Sgo.del Estero } \\
\text { Esclava de Don Francisco Garay 24/4/1786 Matriz Mza } \\
\text { b.5/3/1762 Catedral-Cba. cc Cayetana Gil } \\
\begin{array}{l}\text { f.16/1/1827 Mza. Mulata Libre } \\
\quad \downarrow\end{array}\end{array}$ \\
\hline Madre $\rightarrow$ & 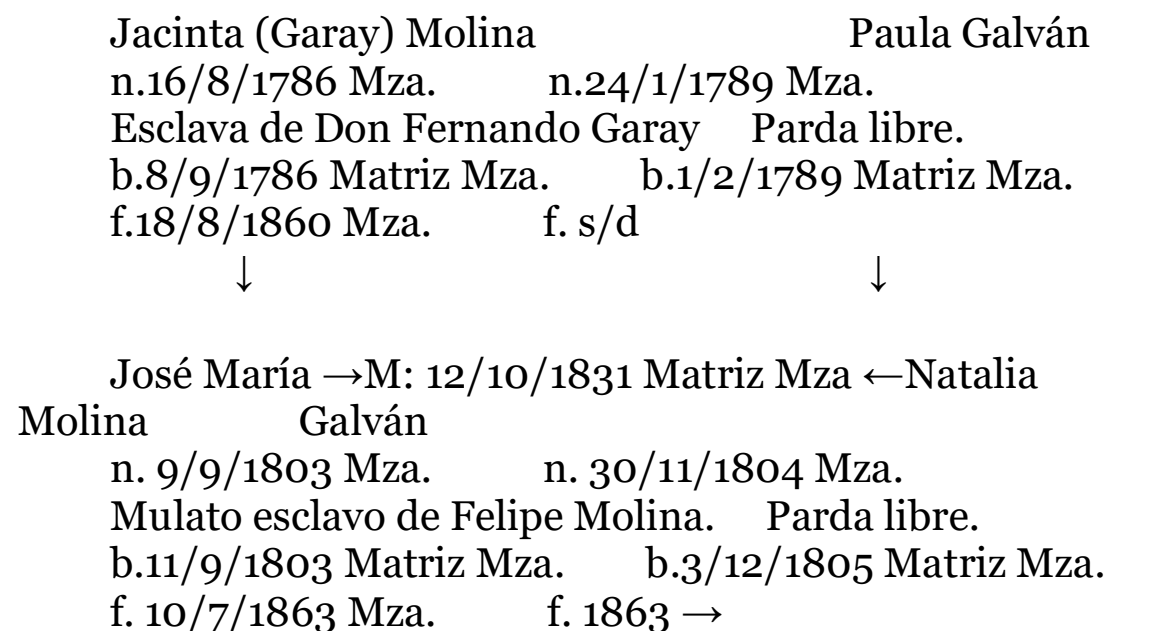 \\
\hline
\end{tabular}

Abreviaturas: $\mathrm{n}=$ nacido/a; $\mathrm{b}=$ bautizado/a; $\mathrm{M}=$ Matrimonio; $\mathrm{f}=$ fallecido/a; $\mathrm{cc}=$ casado/a con; $\mathrm{s} / \mathrm{d}=$ sin datos; Mza = Mendoza; Cba = Córdoba; $\rightarrow=$ en adelante. Fuente: ARZ, Mendoza, Libros de Bautismos, Parroquia Matriz, Libro 11 Bis, Castas, Años 1799/1807, f. 83. ARZ, Mendoza, Libros de Bautismos, Parroquia Matriz, Libro 11 Bis, Castas, Años 1799/1807, f. 152. ARZ, Mendoza, Libros de Matrimonios, Parroquia Matriz, Libro 3, Castas, Años 1814/1835, folio 101v. ARZ, Mendoza, Libros de Defunciones, Parroquia Matriz, Libro n. ${ }^{\circ}$ 19, Años 1862/1867, f. 10.

Poco antes del nacimiento de José María se había realizado un padrón de la población de Mendoza que registró para el año 1802 una población total de 13.796 habitantes, de los que el $37 \%$ eran blancos, el $32 \%$ negros y el $30 \%$ mestizos. La población de origen africano se componía de 2301 negros libres y 2140 esclavos. Esos registros indicaban, por una parte, un importante crecimiento del grupo afrodescendiente respecto de un padrón del año 1777, cuando la población negra sumaba 2129 personas y representaba el 24 \% del total. (Masini Calderón 1962). Por otra parte, señalaban la importancia cuantitativa de la población negra libre a principios del siglo XIX, fenómeno no exclusivo de la ciudad de Mendoza. Un estudio 
de Lyman Johnson sobre las manumisiones en la ciudad de Buenos Aires durante el Virreinato del Río de la Plata demostró que el porcentaje de población esclava que obtenía su libertad cada año, por compra o voluntad del amo, se triplicó entre 1776 y 1810. (Andrews 1989 54). En el Río de la Plata la cantidad de negros libres crecía a un ritmo considerable desde fines del siglo XVIII, y algunas medidas contra el sistema de la esclavitud implementadas en las primeras décadas del XIX, como la prohibición del ingreso de esclavos y la declaración de la Ley de Vientres en 1813, contribuyeron a favor de la preponderancia de los africanos y afromestizos libres.

La multiplicación de la población de origen africano en Mendoza se vinculaba en parte con el crecimiento de la parcialidad mulata desde principios del siglo XVIII. (Coria 2006 66). Lo mismo sucedía en San Juan, la segunda ciudad más importante de la Provincia de Cuyo, con un 78 \% de mulatos entre la población de origen africano en 1777. (Donoso 2016 97). El mestizaje crecía en el Río de la Plata como en otras regiones de Hispanoamérica, y en buena parte estaba ligado a la extensión social de la ilegitimidad. (Twinam 2013 7). Coria encontró que en el período 1710-1775 en Mendoza era corriente la unión matrimonial de negros con blancos e indios, y asoció además la «proliferación del tipo mulato» con las uniones ilegítimas. (64-65). No resulta extraño entonces que José María fuera un mulato de padre no conocido.

Durante los primeros años de su vida José María fue esclavo de Felipe Molina, de quien recibió el apellido. Felipe Molina era un hombre soltero, hacendado, radicado en la Villa de Uspallata, ubicada en el valle del mismo nombre que se extiende entre la precordillera y las altas montañas de los Andes, en el camino entre Mendoza y Santiago de Chile. El 6 de agosto de 1807 Jacinta Molina bautizó en la parroquia Matriz de Mendoza a Tomasa, la única hermana de José María. Tomasa fue registrada como mulata, hija natural de Jacinta y de padre no conocido, de un año y seis meses de edad, esclava de Felipe Molina. ${ }^{14}$ Días después, el 19 de setiembre, falleció don Felipe en su estancia de Uspallata y fue enterrado en la Iglesia de San Francisco de la Ciudad de Mendoza. ${ }^{15}$ Enfermo, en grave estado, Felipe convocó a su hacienda al maestro de postas de la Villa de Uspallata, don Valentín Ortiz, a quien dio poder para testar y nombró primer albacea y tenedor de bienes. En su memoria testamentaria Felipe

\footnotetext{
14 ARZ, Mendoza, Libros de Bautismos, Parroquia Matriz, Libro 11 Bis, Castas, Años 1807/1815, f. 4. 15 ARZ, Mendoza, Libro de Defunciones, Parroquia Matriz, Libro 10, Años 1804/1820, f. 32.
} 
declaró que dejaba libre a su criada Casimira y a su hija Jacinta y sus dos nietos. Además a Casimira le dejó la casa y la huerta, a Jacinta los alfalfares «para que pueda mantener sus hijos por sus buenos servicios»; a ambas criadas dejó también la hacienda de Uspallata con el ganado vacuno, el ovino y las mulas. ${ }^{16}$ Esa disposición testamentaria otorgaba así la manumisión graciosa a la familia compuesta por Casimira, Jacinta, José María y Tomasa Molina, y hacía a estas mujeres acreedoras de importantes propiedades que permitirían el sustento del grupo.

Las fuentes que citamos demuestran que José María Molina fue manumitido por su propietario en 1807 , pese a que algunos historiadores -al trazar una semblanza del capitán Molina en el contexto de la conspiración unitaria de 1835- han vinculado su condición de libre con las disposiciones de las autoridades revolucionarias posteriores a 1810. (González 1964 730). En efecto, esas afirmaciones no se sostienen en documentación histórica sino en el presupuesto de la «redención de la esclavitud» por la revolución de la independencia, como también lo hemos señalado para el caso del coronel Barcala. (Morales y Caballero, 2018).

\section{Ejercicio de derechos}

La memoria testamentaria de Felipe Molina recibió objeciones por parte de sus hermanos y sobrinos, quienes se presentaron a la Justicia como herederos ab intestato solicitando su nulidad. El alcalde ordinario de 1. er Voto de Mendoza, Juan de la Cruz Vargas, abrió un expediente y se tomó declaración al mencionado don Valentín Ortiz y otros testigos para conocer el estado de salud de Felipe al momento de dictar sus disposiciones testamentarias. ${ }^{17}$ También se inventariaron los bienes del finado Felipe Molina. ${ }^{18}$ Esa situación sirvió de marco para que Casimira y Jacinta se agenciaran en favor de su libertad a través de una representación realizada el 16 de febrero de 1808

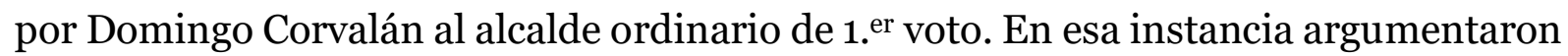
que su libertad era incuestionable, que era demasiado riguroso permanecer privadas

16 Testamentaría Molina Felipe, septiembre 23 de 1807. AGPM, Mendoza, Sección Testamentaria Colonial, Fondo Época Colonial, Carpeta nº 6, Años 1802/1813, Letra M, Documento no 9, f. 4.

17 Testamentaría Molina Felipe, septiembre 23 de 1807. AGPM, Mendoza, Sección Testamentaria Colonial, Fondo Época Colonial, Carpeta n ${ }^{\circ}$ 6, Años 1802/1813, Letra M, Documento no 9, fs. 188.

${ }^{18}$ A partir de la información detallada en el inventario de bienes sobre el terreno donde se emplazaba la casa heredada por Casimira Molina establecimos la ubicación actual del sitio en el cruce de la Av. San Martín y calle Benavente, del lado Este y hacia el Norte. Testamentaría Molina Felipe, septiembre 23 de 1807. AGPM, Mendoza, Sección Testamentaria Colonial, Fondo Época Colonial, Carpeta $n^{\circ} 6$, Años 1802/1813, Letra M, Documento ${ }^{\circ}$ 9, f. $42 v$. 
de ella para contraerse al servicio y trabajo personal para su subsistencia, y solicitaron poder conchabarse, para lo que ofrecieron una fianza con la obligación de Domingo Corvalán. Sin embargo, debieron hacer dos presentaciones más, a través de Pedro Estevan Fret, para reclamar contra la dilación de la causa. Finalmente, el 13 de julio de 1809 el alcalde ordinario de $1 .^{\mathrm{er}}$ voto, Manuel Ignacio Molina, dictó sentencia siguiendo el criterio de ex bono et equo (sic) - de acuerdo con lo correcto y lo bueno-y dispuso que: «se declaran por subsistentes los Legados así de la Libertad como de las demás especies designadas en la expresada Cédula a los esclavos del finado Don Felipe Molina». ${ }^{19}$

El caso de Casimira y Jacinta Molina ilustra una práctica bastante extendida en la región y en Hispanoamérica en el período colonial: el recurso de las esclavas a la justicia para exigir el cumplimiento de sus derechos en casos de litigios por su manumisión, por sevicia o de afronta a su honor. ${ }^{20}$ Más todavía, en un estudio que revisa el acceso de mujeres esclavas a la justicia para reclamar por su libertad en la ciudad de Mendoza en la década revolucionaria de 1810, se demostró su aprovechamiento de las oportunidades y variaciones operadas en el sistema normativo e institucional y su apelación a la nueva legitimidad patriótica y revolucionaria en la argumentación por el derecho a la libertad civil. ${ }^{21}$

Jacinta Molina volvió a apelar a la justicia en abril de 1812, esta vez con una representación contra su madre Casimira Molina. Jacinta se hallaba recluida en una casa de cautela, inhabilitada para el libre ejercicio de sus derechos sobre sus bienes y apartada del cuidado de sus hijos José María y Tomasa, por una disposición judicial a instancias de una imputación de su padre político Juan José Gálvez ${ }^{22}$ que ponía en

19 Testamentaría Molina Felipe, septiembre 23 de 1807. AGPM, Mendoza, Sección Testamentaria Colonial, Fondo Época Colonial, Carpeta n ${ }^{\circ}$ 6, Años 1802/1813, Letra M, Documento no ${ }^{\circ}$, f. 154-156v.

${ }^{20}$ Maribel Arrelucea Barrantes, «Lágrimas, negociación y resistencia femenina: Esclavas litigantes en los tribunales. Lima 1760-1820». Revista Summa Historiae, vol. 2, 2008, pp. 85-102; Carolina González Undurraga, «Los usos del honor por esclavos y esclavas: del cuerpo injuriado al cuerpo liberado (Chile, 1750-1823)». Nuevo Mundo Mundos Nuevos [en línea], Colloques; María Eugenia Chaves, Honor y libertad. Discursos y recursos en la estrategia de libertad de una mujer esclava (Guayaquil a fines del periodo colonial). Gõteborg: Instituto Iberoamericano de la Universidad de Gõteborg, 2001.

${ }^{21}$ Beatríz Bragoni y Orlando Gabriel Morales. «Libertad civil y patriotismo en el Rio de la Plata revolucionario: la experiencia de los esclavos negros en la provincia de Cuyo, 1812-1820». Historia y Sociedad, vol. 30, 2016, pp. 131-167.

${ }^{22}$ En la fuente citada Jacinta Molina se refiere a su padre político usando el apellido materno de aquel, pero en otros documentos él mismo aparece como José de los Dolores Madrid. En la solicitud de autorización para contraer matrimonio con Casimira Molina este dice llamarse José de los Dolores 
juicio su honor y una conducta desarreglada. Ante el alcalde de $2 .^{\circ}$ voto y frente a los miembros del Tribunal de Concordia Jacinta alegó que ya tenía la edad requerida (26 años) para hacerse cargo de sus bienes y que no existía razón justificada para estar recluida, por lo tanto solicitó su libertad, la entrega de sus hijos y la reposición de los bienes para hacer uso de su producto. El 21 de abril el asesor Pedro Nolasco Ortíz dispuso que se pusiera en libertad y fuera de la casa de cautela a Jacinta en atención de haber salido de la pubertad y tener hijos que educar. ${ }^{23}$

El 4 de febrero de 1819 Jacinta presentó una vez más una solicitud al alcalde de $2 .^{\circ}$ voto de Mendoza, esta vez junto a su segundo marido, Paulino Barrionuevo. ${ }^{24} \mathrm{En}$ esa oportunidad los cónyuges solicitaban permiso para hacer un inventario y tasación de los bienes individuales, que fuera homologado y archivado por el escribano actuario, con el objetivo de determinar el capital de cada uno y establecer en el futuro lo que pudiera corresponder a los hijos del matrimonio. Los resultados de aquella diligencia hicieron evidente una importante diferencia de capital a favor de Jacinta (1026 pesos 4 reales contra 403 pesos correspondientes a Paulino), hecho que probablemente impulsaba el uso de esa herramienta.25 Por un testamento de Jacinta sabemos que no tuvo descendencia con Paulino Barrionuevo y que los bienes dotales que había aportado tenían origen en la donación del finado Felipe Molina. ${ }^{26}$

Aunque en los casos mencionados el uso de herramientas legales y el recurso a la justicia involucraban en forma directa a Casimira y a Jacinta, es posible que un discurso sobre derechos estuviera en conocimiento de José María Molina desde su

Madrid, natural de Chile, hijo legítimo de Mateo Madrid, mestizo, y de Gregoria Gálvez, tenida por española. Madrid José Dolores con Casimira Molina, solicitan autorización para contraer matrimonio, 23 de agosto de 1811. AGPM, Mendoza, Sección Judicial Civil, Fondo Época Independiente, Carpeta 67, Años 1811/1815, Letra M, Documento 2, f. 2.

23 Molina Jacinta contra Casimira Molina por entrega de unos bienes, $1 .^{\circ}$ de abril de 1812. AGPM, Mendoza, Sección Judicial, Fondo Época Independiente, Carpeta 67, Años 1811/1815, Letra M, Documento 3, f. 8.

24 Jacinta Molina contrajo matrimonio con el mestizo Cruz Sánchez el 21 de abril de 1814. ARZ, Mendoza, Libros de Matrimonios, Parroquia Matriz, Libro 5, Castas, Años 1806/1821, f. 90v. Jacinta enviudó de Cruz Sánchez y contrajo matrimonio por segundas con el mestizo Paulino Barrionuevo el 14 de setiembre de 1817. ARZ, Mendoza, Libros de Matrimonios, Parroquia Matriz, Libro 5, Castas, Años 1806/1821, f. 134 .

${ }_{25}$ Paulino Rubio, 4 de febrero de 1819. AGPM, Mendoza, Sección Testamentaría independiente, Fondo Época Independiente, Carpeta 6, Documento 7, f. 5.

${ }^{26}$ Escribano Francisco Mayorga, año 1854. AGPM, Mendoza, Protocolo 270, 31 de octubre de 1854, fs. 232-233. 
niñez, y que esto haya configurado su percepción de su inserción social y sus expectativas para trazar su trayectoria social.

\section{Matrimonio y atributos de movilidad}

En un padrón de población de 1814 de la ciudad de Mendoza, Casimira, Jacinta, José María y Tomasa Molina fueron registrados en el Cuartel n. ${ }^{\circ} 13,{ }^{27}$ como habitantes de una misma casa encabezada por José de los Dolores Madrid, un arriero mulato28 casado con Casimira el 27 de octubre de 1811.29 En otro padrón realizado en el año 1823 quienes encabezaban la casa eran Paulino Barrionuevo, panadero, y Jacinta Molina. 30 José María ya no habitaba con su abuela y su madre, sabemos que en ese momento se desempeñaba como soldado en el Cuerpo de Cívicos Pardos de Mendoza.

José María Molina contrajo matrimonio con Natalia Galván, una mujer de similar condición social, hija natural, mestiza y libre, el 12 de octubre de 1831 en Mendoza. La elección de un consorte de igual o más favorable condición social era fundamental para la construcción de una familia entre la población africana en el contexto de la esclavitud y de la desigualdad social que imponía el origen (Grubessich; Coria; Chaves). El matrimonio bautizó tres hijos: María Eustaquia Corina, nacida el 3 de febrero de 1833; ${ }^{31}$ Isabel Adelaida Antonia, nacida el 26 de marzo de 1834; ${ }^{22}$ y Carlos Federico, nacido el 30 de mayo de 1835. 33 No encontramos otros registros que den cuenta de su vida o muerte, aunque suponemos que todos fallecieron a corta edad. En el sumario por conspiración contra el gobierno realizado a Molina en julio de 1835 no se mencionó que tuviese hijos, referencia que sí se hizo respecto del reo Barcala. Por

\footnotetext{
${ }_{27}$ Padrón del Cuartel n. ${ }^{\circ}$ 13. AGPM, Mendoza, Sección Gobierno, Fondo Época Independiente, Carpeta 13, Censos 1810/1814, Documento 20, f. 5 .

${ }_{28}$ Por las informaciones que disponemos deducimos que Juan José Galbes y José de los Dolores Madrid podrían ser la misma persona, en un caso con el apellido de la madre y en otro del padre. Madrid José Dolores con Casimira Molina, solicitan autorización para contraer matrimonio, 23 de agosto de 1811. AGPM, Mendoza, Sección Judicial Civil, Fondo Época Independiente, Carpeta 67, Años 1811/1815, Letra M, Documento 2, f. 2.

${ }^{29}$ ARZ, Mendoza, Libro de Matrimonios, Parroquia Matriz, Libro 5, Castas, Años 1806/1821, f. 65 v.

$3^{\circ}$ Padrón del Cuartel n. ${ }^{\circ}$ 3. AGPM, Mendoza, Sección Gobierno, Fondo Época Independiente, Carpeta 14, Censos 1823/1824, Documento 62, f. 8.

${ }^{31}$ ARZ, Mendoza, Libros de Bautismos, Parroquia Matriz, Libro 18, Castas, Años 1827/1833, f. 376. ARZ, Mendoza, Libros de Bautismos, Parroquia Matriz, Libro 19, Castas, Años 1833/1836, f. 37. ARZ, Mendoza, Libros de Bautismos, Parroquia Matriz, Libro 19, Castas, Años 1833/1836, f. 376.

$3^{2}$ ARZ, Mendoza, Libros de Bautismos, Parroquia Matriz, Libro 19, Castas, Años 1833/1836, f. 37. ARZ, Mendoza, Libros de Bautismos, Parroquia Matriz, Libro 19, Castas, Años 1833/1836, f. 37. 33 ARZ, Mendoza, Libros de Bautismos, Parroquia Matriz, Libro 19, Castas, Años 1833/1836, f. 118.
} 
las informaciones que constan en ese expediente judicial sabemos que para esa fecha Molina estaba retirado del servicio activo, sabía leer y escribir, ejercía el oficio de sastre, y padecía una enfermedad.

Aunque no hallamos otros registros de bautismo de hijos/as del matrimonio Molina-Galván, con certeza que tuvieron al menos una hija más, que habría nacido alrededor de 1835. Tres testamentos de Faustina Molina Galván (en 1883, 1889 y 1908) indican que ella fue hija legítima de José María y Natalia y que en esos momentos no tenía otros hermanos. ${ }^{34} \mathrm{El}$ testamento de José María Molina realizado en marzo de 1862 confirma esa información acerca de una única hija legítima y universal heredera, y agrega que tuvo cuatro hijos no legítimos llamados Críspula, José María, Jesús María y Criselda Molina. $35 \mathrm{El}$ mismo documento permite saber que José María fue hermano cófrade del Convento de la Merced, aunque no hemos podido reunir otras informaciones al respecto. ${ }^{36}$

En su testamento José María Molina declaró ser preceptor de la Escuela de primeras letras del barrio de la Chimba (correspondiente al actual departamento de Las Heras, del Área Metropolitana de Mendoza), empleo por el que el estado provincial le adeudaba los sueldos de 14 meses. El testamento disponía que los albaceas cobraran al estado esa deuda y otras a particulares; y, por otra parte, que se pagaran conforme a la ley de la provincia las imposiciones en favor de la educación pública de primeras letras.

Una lista de útiles comprados para la Escuela del 1. ${ }^{\text {er }}$ Departamento de Campaña (actual departamento Las Heras) por disposición del director y firmada por José María Molina, con fecha del 3 de mayo de 1850 y dirigida al presidente de la Junta de Beneficencia, confirma que este trabajó en esa escuela de primeras letras. Es probable

\footnotetext{
34 Escribano Ángel Navarro, año 1883. AGPM, Mendoza, Protocolo 396, 17 de abril de 1883, fs. 174-174v. Escribano Ángel Navarro, año 1889. AGPM, Mendoza, Protocolo 453, 2 de setiembre de 1889, fs. 1108v. Escribano Ramón R. Videla, tomo 2. AGPM, Mendoza, Protocolo 844, 2 de setiembre de 1908, fs. 537. 35 Escribano Francisco Mayorga, año 1862. AGPM, Mendoza, Protocolo 299, 3 de marzo de 1862, fs. 29v31.

${ }^{36}$ La existencia de cofradías de negros/as o con participación de estos/as es una cuestión todavía desconocida en el caso de Mendoza, la falta de documentación y las restricciones de acceso a los archivos eclesiásticos favorecen esa falta, a más del desinterés que ha tenido la historiografía local por estos temas. Para otras ciudades del Río de la Plata, especialmente Buenos Aires, se han logrado importantes avances en el conocimiento de esos espacios de sociabilidad. Véase Miguel Ángel Rosal, Africanos y afrodescendientes; y Alex Borucki, De compañeros de barco.
} 
que ejerciera esa actividad hasta el momento en que elaboró su testamento en marzo de 1862 o incluso hasta su muerte a causa de epilepsia el 10 de julio de 1863.

Faustina Molina hizo su primer testamento en 1883, declaró ser católica apostólica romana y dispuso por único heredero a su marido don Raimundo Talaguirre, en ese momento ella vivía en el barrio de la Chimba. En el segundo testamento, de 1889, declaró haber estado casada con Talaguirre, sin tener sucesión, y estar casada por segunda vez con don Antonio Villarruel, también sin hijos. En el de 1908 dispuso que por no tener herederos forzosos su Albacea repartiera sus bienes entre las personas indigentes o menesterosas. Ninguno de estos documentos notariales fue firmado por Faustina, por no saber hacerlo; y no hay en ellos informaciones que permitan deducir en forma directa su afrodescendencia si no se conociera el origen de su padre. La condición de esclavo al nacer de José María Molina parecía haberse borrado de la memoria familiar en la trayectoria social entre 1803 y 1908, o al menos los últimos documentos notariales de José María y de su hija Faustina no dejaban marcas de ese pasado.

\section{Milicia}

\section{Incorporación a las armas}

Todavía no contamos con documentos que permitan establecer fehacientemente la fecha de alistamiento de José María Molina en el Cuerpo de Cívicos Pardos de Mendoza, aunque sí podemos asegurar que no fue un esclavo rescatado por el estado para las armas. Deducimos que Molina se alistó después del año 1817, a partir de cumplir los 14 años, edad mínima de aptitud para las armas. En mayo de 1822 Molina fue registrado con el rango de soldado en una lista militar del Segundo Tercio de Cívicos, tal como se denominó a los cívicos pardos a partir de 1820.37 Se trata de una relación de los oficiales de Infantería que recibieron escudos y medallas por su participación en la campaña de San Juan y la batalla de Punta del Médano contra las fuerzas del caudillo chileno José Miguel Carrera ${ }^{8}$ en setiembre de 1821. En la lista,

\footnotetext{
${ }^{37}$ Según Hudson, historiador local decimonónico, ese cambio de nombre de los cívicos pardos fue un gesto democrático de las autoridades para evitar la referencia al color racial (310).

${ }^{38}$ José Miguel Carrera y Verdugo (Santiago de Chile, 1785-Mendoza, 1821) fue un militar y referente de las élites políticas chilenas que se destacó en el proceso de la independencia de Chile, desempeñándose entre 1811 y 1813 como presidente de la Junta de Gobierno, en una fallida primera fase de la emancipación política de la monarquía española. En 1814 protagonizó la derrota de los patriotas
} 
elaborada por Lorenzo Barcala, se anota un escudo en favor de José María Molina por su acción en San Juan; y es el único que aparece indicado como soldado en una lista de oficiales. 39 La acción militar que derrotó a las tropas carrerinas fue muy celebrada en Mendoza y del otro lado de la cordillera, pues Carrera suponía una amenaza para el gobierno provincial y el chileno, y las autoridades premiaron a los oficiales destacados con medallas de oro y plata (Peña y Lillo 1937 6o-61).

El Segundo Tercio de Cívicos se destacó en otras acciones durante la década de 1820, y mulatos como José Antonio Sosa, Lorenzo Barcala y el propio José María Molina trazaron una carrera militar ascendente a la par de esa notabilidad del cuerpo armado. Los dos primeros llegaron a ser comandantes de esa fuerza. El prestigio de la institución no iba desasociado de mayores expectativas de los milicianos que hacían la carrera de las armas como profesión, y su poder militar y la preeminencia de sus fueros tensaban los nervios de la élite política mendocina (Peña y Lillo 1937 108, 140).

En diciembre de 1823 la Honorable Junta de Representantes de Mendoza recibió un petitorio del gobernador Pedro Molina para que se otorgue el derecho a sufragio a los oficiales y soldados de la provincia (Peña y Lillo 107). En los primeros días de ese mes, en el marco de algunas reformas al régimen electoral, se dispuso que todo ciudadano habilitado para votar por la ley debía tramitar su boleta de registro, sin distinción de persona; y «que todo oficial menor de edad y no emancipado, no tiene voz activa». (Hudson 2008 442). Poco después, en febrero de 1824, el gobernador Molina tomó conocimiento de un movimiento contrario a su gobierno e inició un sumario indagatorio al sargento mayor Lorenzo Barcala y al del mismo rango Juan Bautista Chenaut. El primero señaló que había malestar entre los milicianos por un decreto del gobierno que afectaba a los oficiales. Al respecto, se ha señalado que

chilenos frente a los españoles en la batalla de Rancagua, hecho que representó la caída de la llamada «Patria Vieja» (1810-1814) y el refugio de los revolucionarios en la ciudad de Mendoza. Llegó a esta ciudad junto a un contingente de militares y vecinos entre quienes se destacaba Bernardo O'Higgins, con quien mantenía diferencias políticas. El Gobernador Intendente de Cuyo, José de San Martín, estableció relaciones con O'Higgins y dispuso que Carrera fuera enviado a Buenos Aires. Entre 1814 y 1821 Carrera quedó desplazado de la conducción de la guerra de independencia y se involucró en enfrentamientos armados por el control del poder en el Río de la Plata y por el retorno a Chile. En agosto de 1821 Carrera fue derrotado en la batalla del Médano y posteriormente procesado por un tribunal militar y condenado a muerte. El 4 de septiembre fue fusilado en Mendoza. Véase una biografía en Beatríz Bragoni, José Miguel Carrera. Un revolucionario chileno en el Río de la Plata (Buenos Aires: Edhasa, 2012).

39 Relación de los Oficiales del 2. ${ }^{\circ}$ Tercio de Cívicos de Infantería, con escudos y medallas, con expresión de clases que tenían cuando se les dio, 30 de mayo de 1822. AGPM, Mendoza, Sección Militar, Fondo Época Independiente, Carpeta 457, Documento 87, f. 1. 
posiblemente la indisposición de los milicianos se debía a la decisión de la Honorable Sala de Representantes de mantener el límite de edad para votar en los 25 años, aún para los enrolados en los cuerpos cívicos, contra una representación que habían hecho los jefes de regimiento para que se los habilitara para sufragar. Ese mismo año, habiendo renunciado al gobierno Pedro Molina por una crisis política y asumido en su lugar José Albino Gutiérrez, el Primer Tercio y Segundo Tercio de Cívicos se acuartelaron y empujaron al flamante gobernador a abandonar su cargo a solo un mes de asumido, entregando el gobierno provincial al coronel Juan Lavalle. (Hudson 4043)

No tenemos registro de la experiencia de José María Molina en todos los hechos mencionados, y no tenemos información militar de él hasta el año 1835, pero parece claro que los milicianos mulatos se entendían con las cuestiones políticas a nivel local y que la oficialidad exigía participación política a través del sufragio. Por otra parte, por las informaciones vertidas en el expediente judicial por la conspiración de 1835, es evidente que en el marco del enfrentamiento entre unitarios y federales, después de 1828, Molina optó por el unitarismo.40

\section{Política y conspiración}

El expediente del sumario contra Lorenzo Barcala y sus cómplices José María Molina, Pedro Bombal y Juan Montero en la conspiración proyectada en 1835 contra el gobierno provincial no contiene en todo su texto las palabras negro, mulato, pardo, cívicos. Es decir, el documento no da cuenta de una conspiración de los cívicos mulatos o de una organización político-militar con base en identificaciones étnico-raciales. Sin embargo, la comunicación entre el reo principal y su cómplice principal (dos mulatos libres, artesanos y militares) deja ver algunas solidaridades, compromisos y articulaciones que tienen un vínculo no evidente con múltiples pertenencias (militar,

\footnotetext{
40 Los federales postulaban una organización política basada en una asociación voluntaria de las provincias que delegara algunas atribuciones en un gobierno federal nacional, conservando niveles de autonomía provincial. Los unitarios planteaban un sistema que derivaba del centralismo del período revolucionario y postulaba una unidad de régimen con un gobierno nacional centralizado en Buenos Aires. Los unitarios estaban representados en forma predominante por la élite económica, política, intelectual y militar de Buenos Aires y de las principales ciudades del interior. Los federales estaban representados por líderes (caudillos) con apoyo de sectores populares y con menor adhesión de intelectuales, políticos y vecinos distinguidos.
} 
de oficio, étnico-racial) que atravesaron a los afromestizos libres movilizados por las guerras de independencia y civiles en el Río de la Plata.

El elemento de prueba principal en el expediente judicial de 1835 fue una carta original enviada por el coronel Barcala, el día 3 de julio de ese año desde su residencia en San Juan, al capitán José María Molina, radicado en Mendoza. En ese texto se planteaban los principales objetivos del movimiento proyectado: cambiar la administración política de la provincia y desterrar a su comandante de armas -el general Félix Aldao-, elaborar una constitución provincial, adelantar tratados con Chile y hacer acuerdos con las provincias a excepción de la de Buenos Aires, para bloquear la influencia del gobernador Juan Manuel de Rosas. Además, en ese texto Barcala hacía algunas solicitudes a Molina:

Amigo mío: [...] No cese de darme todas las noticias que le sean posibles, y provechosas muy particularmente sobre armada, tropa, y desagrado o gusto para servirles estos; hágase amigo con algunos músicos, sargentos, etcétera, no descuide nada y vea si puede venir, para informarse más pronto en todo, por no poderlo hacer en las cartas [...] Espíe bien la opinión pública en todos Usted tiene facilidad para esto, y no deje de escribirme lo que observe a este fin... ${ }^{41}$

En otro pasaje de la misiva Barcala aseguraba a Molina que no esperaba la inmediata comprensión de sus paisanos, pero que en algún momento, al corroborar el respeto por las vidas y las propiedades, aquellos responderían con gratitud: «serán muy pocos es verdad, pero nosotros con la experiencia que tenemos tan triste, no necesitaremos tanto de ellos, ya Usted me entiende».42

Se puede percibir en esas líneas una identificación y entendimiento a partir de una experiencia compartida que podría ser étnica/racial, militar y/o política, asociada a su condición social de mulatos libres, vinculados por el oficio de sastre43 y por una

\footnotetext{
${ }^{41}$ Coronel Barcala, 1835. Archivo Nacional Histórico (ANH), Santiago de Chile, Volumen CXL, Fondo Vicuña Mackenna, fs. 136-137. El destacado en cursiva es nuestro.

${ }^{42}$ Coronel Barcala, 1835. ANH, Santiago de Chile, Volumen CXL, Fondo Vicuña Mackenna, f. 136v. El destacado en cursiva es nuestro.

$43 \mathrm{El}$ oficio de Molina surge de las declaraciones de los testigos en el sumario indagatorio de 1835, mientras que el de Barcala surge de una lista militar del año 1815. Coronel Barcala, 1835. Archivo Nacional Histórico (ANH), Santiago de Chile, Volumen CXL, Fondo Vicuña Mackenna, f. 139v. Estado de los individuos que comprenden la segunda compañía del cuerpo de cívico de pardos de Mendoza, con expresión de clases, nombre, estado, patria, conducta y calidad, Mendoza, 15 de junio de 1815. AGPM, Mendoza, Sección Militar, Fondo Época Independiente, Carpeta 456, Documento 96, f. 1.
} 
trayectoria en la milicia de cívicos pardos. También inferimos un supuesto de Barcala en el argumento de la misiva: la potencial adhesión a la causa de los militares músicos y sargentos, posiblemente afromestizos; y el reconocimiento de una habilidad de Molina que solo podía surgir de la educación y de un acceso al discurso público sobre la base en una posición social singular (Morales y Caballero, Integración social de afromestizos).

Otro sastre, Gabriel Ferreira, natural de la ciudad de Córdoba, culto, de 27 años de edad en 1835, probablemente hijo legítimo de los esclavos Estanislao Ferreyra y María Ferreyra, 44 fue involucrado en la causa por una declaración del propio Barcala, que lo señaló como un mensajero ocasional para hacer llegar una solicitud a Molina. Ferreira fue arrestado e interrogado, y por su declaración sabemos que fue el mismo Barcala quien, al encontrarse circunstancialmente ambos en San Juan, le confió sus intereses, lo intentó comprometer como informante y le pidió entregar un mensaje a Molina. Es evidente que Barcala debía conocer a Ferreira y entender que tenían una confianza suficiente como para confiarle sus ideas conspirativas. Aunque Ferreira aseguró que solo se conocían de vista y que nunca había estado alistado en una fuerza militar bajo sus órdenes, de modo que su confianza se debía al solo hecho de saberlo amigo de Molina.45

Por su parte, en defensa del capitán Molina, el defensor general de pobres, León Correa, sustanció sus argumentos mediante la apelación a los conceptos de «consentimiento político», «dependencia voluntaria» y «amistad», 46 con los que pretendió justificar la relación de su defendido con Barcala.

\section{Destierro y regreso}

El fiscal del proceso judicial contra Barcala y sus cómplices por conspiración, Clemente Cárdenas, solicitó para Molina la pena de destierro de la provincia por haber comprometido su voluntad en colaborar con el coronel.47 El asesor y auditor de Guerra,

\footnotetext{
44 Archivo Eclesiástico del Arzobispado de Córdoba (ARZ-C), Córdoba, Libro bautismos, Iglesia Catedral de Córdoba, Libro 10, Naturales, Años 1807/1811, f. 13 v. No hemos podido contrastar este documento con otras fuentes que permitan confirmar con mayor certeza que este registro corresponda al Gabriel Ferreira en cuestión, pero es muy probable que así sea.

45 Coronel Barcala, 1835. ANH, Santiago de Chile, Volumen CXL, Fondo Vicuña Mackenna, fs. 178v-179v.

${ }^{6} 6$ Coronel Barcala, 1835. ANH, Santiago de Chile, Volumen CXL, Fondo Vicuña Mackenna, f. 210.

47 Coronel Barcala, 1835. ANH, Santiago de Chile, Volumen CXL, Fondo Vicuña Mackenna, f. 221.
} 
Juan de la Cruz Vargas, recomendó al tribunal que sentenciara a Molina «a salir para Reynos extranjeros, como lo es por ejemplo, la República de Chile, con la calidad de proscripto de esta provincia, y ponerle fuera de la Ley, si volviese a ella» 48 . La Comisión Militar aceptó la recomendación del asesor y el 31 de julio sentenció el destierro del capitán Molina.

Don Pedro José Balderrama se presentó el 8 de agosto ante el escribano público de Gobierno, Minas y Registros para dar cuenta de que el capitán Molina no podía verificar la marcha en el término establecido por sufrir una grave enfermedad. $49 \mathrm{El}$ gobernador concedió a Molina dos meses de plazo para recuperar su salud bajo fianza de dos mil pesos a cargo del representante Balderrama. El 10 de octubre el juez Pedro José Pelliza, por petición del defensor general de pobres, concedió al capitán Molina un mes más para su cura. $5^{\circ} \mathrm{El} 4$ de diciembre se verificó la salida de Molina de la República y se levantó la fianza. ${ }^{1}$

A principios de abril del año siguiente don José María Molina fue detectado en la villa de Jachal sin la licencia correspondiente, arrestado, y enviado a la cárcel pública de la ciudad de San Juan. Inmediatamente las autoridades sanjuaninas pusieron en alerta al gobernador de la provincia de Mendoza sobre la posibilidad de maniobras de «los enemigos del orden».52 El gobernador Pedro Molina respondió dos días después enviando copia de la sentencia contra Molina y solicitando una indagación al reo para averiguar sus planes. 53

El día 17 de abril el coronel Juan Agustín Cano ejecutó el interrogatorio. Al ser preguntado por su oficio y condición, el oficial José María Molina, dijo ser sastre y desconocer su condición. Preguntado por los planes de los unitarios dentro y fuera de la República,54 dijo desconocer; y sobre su relación con el finado Lorenzo Barcala,

\footnotetext{
${ }^{48}$ Coronel Barcala, 1835. ANH, Santiago de Chile, Volumen CXL, Fondo Vicuña Mackenna, f. 224v.

49 Escribano Fernando Otero, año 1835. AGPM, Mendoza, Protocolo 217, folio 24.

50 Ídem.

51 Ídem.

52 Del gobierno de San juan al Gobernador y Capitán de la Provincia de Mendoza, 28 de febrero de 1836. AGPM, Sección Gobierno, Fondo Época Independiente, Carpeta 684, Provincia de San Juan, Años 1821/1839, Documento 55, f. 8.

53 Archivo General de la Provincia de San Juan (AGPSJ), Libro 165, Fondo Histórico, fs. 64-65.

54 En ese momento en Chile había un importante contingente de exiliados militares, intelectuales y líderes políticos unitarios.
} 
sostuvo que era por amistad y uniformidad de opiniones. También adujo desconocimiento respecto de su destierro a un destino específico y argumentó que entendía que no podía volver a Mendoza pero sí a otra provincia. Sostuvo que encontraba de paso entre Copiapó y Tucumán, y que se dirigía a esa ciudad para radicarse en la casa de su suegra, donde tenía arreglado un trabajo que le permitiría subsistir.55

\section{Conclusiones}

Algunas de las informaciones de contexto expuestas dejan ver que la sociedad mendocina experimentó un proceso de transformación en el pasaje del período colonial al independiente, escenario en el que se configuraron y desenvolvieron las trayectorias sociales de José María Molina y de su entorno familiar y social. Parte del cambio estuvo dado por el crecimiento de la población africana y afromestiza entre 1777 y 1812, con 24 y 33 por ciento respectivamente de población negra, estimulado por el auge del tráfico de esclavos hacia fines del siglo XviII en el Río de la Plata -con Mendoza como punto de conexión del comercio entre las ciudades de Buenos Aires, Santiago, Valparaiso y Lima - y también por un extendido mestizaje que contribuyó al crecimiento del grupo afromestizo. A principios del siglo XIX una buena parte de esa población, introducida como esclava o nacida de esclavizados, había alcanzado la condición de libre y procuraba mejores en sus condiciones de vida. Según cálculos de Masini Calderón, hacia 1823 los libres casi duplicaban a los que continuaban esclavizados. ${ }^{56}$ La experiencia familiar de José María Molina asistió a ese fenómeno y también a una progresiva declinación de la población negra, calculada para 1823 en un $12 \%$. Ese declive cuantitativo en los registros poblacionales fue interpretado por Masini, no sin subestimar la desigualdad social de la época, como una tendencia igualitaria de una sociedad hispánica que estaba incorporando a los descendientes de africanos (La esclavitud negra en Mendoza).57

La historiografía reciente ha mostrado que la sociedad cuyana y mendocina atravesó importantes cambios sociales y políticos a partir de la revolución de 1810 en

55 AGPSJ, Libro 165, Fondo Histórico, f. 68-72. Es destacado con cursivas es nuestro.

${ }^{6}$ José Luis Masini Calderón, «La esclavitud negra en San Juan y San Luis. Época independiente». Revista de Historia Americana y Argentina, vols. 7/8, 1962-1963, pp. 177-210.

57 Ídem. 
el Río de la Plata, entre estos la apertura de nuevas oportunidades sociales a partir de innovaciones normativas e institucionales - como las relativas a la abolición gradual de la esclavitud- y una politización de los sectores populares. ${ }^{88}$ La militarización desplegada desde el arribo de José de San Martín en 1814 a la flamante Gobernación Intendencia de Cuyo y con la creación del Ejército de los Andes, introdujo notables acciones de gobierno y repercutió incluso en las formas de sociabilidad. 59 En ese contexto, ningún varón de origen africano en edad de tomar las armas, ya fuese libre o esclavo, pudo excluirse del servicio militar. (Masini 1962). Los mulatos libres, en particular, como Lorenzo Barcala y José María Molina, fueron reclutados para el servicio en la milicia cívica y tuvieron la posibilidad de hacer una carrera militar. La política sanmartiniana trascendió los cuarteles y penetró en la sociedad modificando los hábitos y las formas que habían prevalecido en la sociedad colonial, contribuyó a forjar una opinión general favorable a la revolución y una percepción social de ser partícipes de tiempos modernos orientados por las ideas de la Ilustración. (Bragoni 2010). En esa coyuntura, apelando a valores liberales con legitimidad política y social, algunos esclavos y libertos, varones y mujeres, elaboraron estrategias, argumentos y se agenciaron, en forma individual o colectiva, a favor del acceso a la libertad o de los derechos adquiridos. (Bragoni y Morales 2016).

En ese contexto, la trayectoria social de José María Molina y de parte de su familia deja ver un lento proceso de integración social desde el estado de esclavitud hacia la libertad, una asunción de derechos y un agenciamiento frente a la justicia para reclamar por su ejercicio efectivo. Posiblemente las experiencias de Casimira y Jacinta influyeron en las concepciones de José María respecto de la posición social y en sus expectativas sociales. La inserción social en instituciones prestigiosas de la sociedad independiente, como la milicia de cívicos pardos, debió contribuir también a esa conciencia de pertenencia a un mundo social diferente al de los esclavos. La trayectoria social del pardo libre Lorenzo Barcala a partir de su ingreso a la milicia cívica hacia

\footnotetext{
${ }_{58}^{8}$ Beatríz Bragoni, «Esclavos, libertos y soldados: la cultura política plebeya en Cuyo durante la revolución». ¿Y el pueblo dónde está?. Contribuciones para una historia popular de la Revolución de Independencia en el Río de la Plata. ed. Raúl O. Fradkin. Buenos Aires: Prometeo, 2009, pp. 107-150; Beatríz Bragoni, «Esclavos insurrectos en tiempos de revolución (Cuyo 1812)». «Negros de la patria». Los afrodescendientes en las luchas por la independencia en el antiguo Virreinato del Río de La Plata. eds. Silvia Mallo C. e Ignacio Telesca. Buenos Aires: SB, 2010, pp. 113-130.

59 Hebe Molina y Fabiana Varela. «La vida social y cultural mendocina en el siglo XIX». Panorama de las letras y la cultura en Mendoza. dir., Marta Elena Castellino. Mendoza: Universidad Nacional de Cuyo, 2013, pp. 297-316.
} 
1815 deja ver el rol fundamental de su inserción militar en la posibilidad económica de construir una familia de afromestizos libres y en el logro de movilidad social para su familia. También en la adquisición de prestigio social y en la posibilidad de vincularse con las élites políticas y militares cuyanas, atributos que hacían de Barcala un actor excepcional que se había forjado en la carrera de las armas abierta por la militarización de Cuyo. ${ }^{60}$ Por su parte, la trayectoria de José María Molina, si bien menos extraordinaria que la de Barcala, permite apreciar la centralidad de la milicia para forjar solidaridades, identificaciones políticas y trazar posibilidades de integración en el largo plazo. En el caso de su familia, el acceso a la libertad y el acceso a la propiedad, por la misma circunstancia - la muerte y la herencia del hacendado Felipe Molina-, debieron incidir especialmente para desprenderse al menos parcialmente de las amarras de la servidumbre. El matrimonio de José María Molina y Natalia Galván, afromestizo y mestiza libres, no dejó registros documentales explícitos de un pasado ligado a la esclavitud.

La trayectoria social del coronel Barcala se cerró con su fusilamiento en 1835 al reconocer su participación en el plan para remover a las autoridades gubernamentales provinciales, mientras que el capitán Molina pudo regresar del destierro y proyectarse por fuera de las armas como un ciudadano ligado a las luces de la instrucción educativa. Aunque la historiografía sostuvo hasta ahora que Barcala fue esclavo, hemos demostrado que si no desde su nacimiento al menos desde muy corta edad Lorenzo fue libre y criado por el matrimonio de Cristóbal Barcala, escribano del Cabildo de Mendoza. ${ }^{61}$ Esas características no hacían de Barcala un descendiente de africanos corriente, como podía ser el caso de Molina, pero los atributos sociales conseguidos por el coronel estuvieron ligados directamente a su propia agencia. José María Molina, por su parte, nacido esclavo y criado por su madre y abuela exesclavas, sin ser un militar destacado de las guerras de independencia y las guerras civiles como su fallecido amigo Barcala, hacia el final de su vida podía dar cuenta de un pasado miliciano en una institución prestigiosa y de haber alcanzado una movilidad social ascendente con un empleo en una institución prestigiosa como una escuela de primeras letras. En otras palabras, Molina había aprovechado las oportunidades y se había gestado una trayectoria de integración social.

\footnotetext{
6o Morales y Caballero, Movilidad social de afromestizos...

${ }^{61}$ Morales y Caballero. "Movilidad social de afromestizos movilizados...», ob. cit.
} 


\section{Obras citadas}

\section{Fuentes}

Archivo del Arzobispado de Mendoza (ARZ), Mendoza, Argentina, Libro de Bautismos de Castas, Libro de Defunciones, Libro de Matrimonios de Castas, Parroquia Matriz.

Archivo Eclesiástico del Arzobispado de Córdoba (ARZ-C), Córdoba, Argentina, Libro de Bautismos de Naturales.

Archivo General de la Provincia de Mendoza (AGPM), Mendoza, Argentina. Secciones Gobierno, Militar, Protocolos, Bajas y Solicitudes de Retiro, Testamentaría Independiente, Fondo Época Independiente.

Archivo General de la Provincia de Mendoza (AGPM), Mendoza, Argentina. Sección Testamentaria Colonial, Fondo Época Colonial.

Archivo GENeral de la Provincia de SAN JuAN (AGPSJ), San Juan, Argentina. Libro 165, Fondo Histórico.

Archivo Nacional Histórico (ANH), Santiago de Chile, Chile, Volumen cXl, Fondo Vicuña Mackenna.

\section{Bibliografía}

Andrews, George Reid. «The Afro-Argentine Officers of Buenos Aires Province, 18001860. The Journal of Negro History, vol. 64, n. ${ }^{\circ}$ 2, 1979, pp. 85-100.

Andrews, George Reid. Los afroargentinos de Buenos Aires. Buenos Aires: Ediciones de la Flor, 1989.

Arrelucea Barrantes, Maribel. «Lágrimas, negociación y resistencia femenina: Esclavas litigantes en los tribunales. Lima 1760-1820». Revista Summa Historiae, vol. 2, 2008, pp. 85-102.

Bernand, Carmen. «Los olvidados de la revolución: el Rio de la Plata y sus negros». Nuevo Mundo Mundos Nuevos, Colloques, 2010. doi: $10.4000 /$ nuevomundo.58416

Bonilla, Heraclio. Indios, negros y mestizos en la independencia. Bogotá: Planeta Colombiana-Universidad Nacional de Colombia, 2010.

Borucki, Alex. De compañeros de barco a camaradas de armas. Identidades negras en el Río de la Plata, 1760-186o. Buenos Aires: Prometeo, 2017.

Borucki, Alex; Karla Chagas y Natalia Stalla. "Abolición y esclavitud en el Estado Oriental del Uruguay, 1830-1860». «Negros de la patria». Los afrodescendientes en las luchas por la independencia en el antiguo Virreinato del Río de La Plata. eds., Silvia C. Mallo e Ignacio Telesca. Buenos Aires: SB, 2010.

Bragoni, Beatriz. «Esclavos, libertos y soldados: la cultura política plebeya en Cuyo durante la revolución». ¿Y el pueblo dónde está?. Contribuciones para una 
historia popular de la Revolución de Independencia en el Río de la Plata. ed. Raúl O. Fradkin. Buenos Aires: Prometeo, 2009, pp. 107-150.

Bragoni, Beatriz. San Martín: De soldado del Rey a héroe de la nación. Buenos Aires: Sudamericana, 2010.

Bragoni, Beatriz. «Esclavos insurrectos en tiempos de revolución (Cuyo 1812)». «Negros de la patria». Los afrodescendientes en las luchas por la independencia en el antiguo Virreinato del Río de La Plata. eds. Silvia Mallo C. e Ignacio Telesca. Buenos Aires: SB, 2010, pp. 113-130.

Bragoni, Beatríz. José Miguel Carrera. Un revolucionario chileno en el Río de la Plata. Buenos Aires: Edhasa, 2012.

Bragoni, Beatriz. "Participación popular en Cuyo, siglo XIX». Hacer política. Participación popular en la Argentina del siglo XIX. eds., Raúl Fradkin y Gabriel Di Meglio. Buenos Aires: Prometeo, 2013. 205-238.

Bragoni, Beatriz y Orlando Gabriel Morales. «Libertad civil y patriotismo en el Río de la Plata revolucionario: la experiencia de los esclavos negros en la provincia de Cuyo, 1812-1820». Historia y Sociedad, vol. 30, 2016, pp. 131-167.

Caballero, Luis César. Los negros esclavos en Mendoza, algunas genealogías. Mendoza: Cuadernos de Genealogía de Cuyo-SS\&CC Ediciones, 2010.

Candioti, Magdalena. «Abolición gradual y libertades vigiladas en el Río de la Plata. La política de control de libertos de $1813{ }^{»}$. Corpus, vol. 6, n. ${ }^{\circ}$ 1, 2016. Recuperado a partir de: http://corpusarchivos.revues.org/1567

Comadrán Ruiz, Jorge. «Las milicias regladas de Mendoza y su importancia en la organización del Ejército de los Andes». Cuaderno CEIFAR, 1, 1978, pp. 65-74.

Chamosa, Oscar. "To Honor the Ashes of Their Forebears": The Rise and Crisis of African Nations in the Post-Independence State of Buenos Aires, 1820-1860». The Americas, vol. 59, n. ${ }^{\circ}$ 3, 2004, pp. 347-378.

Chaves, María Eugenia. Honor y libertad. Discursos y recursos en la estrategia de libertad de una mujer esclava (Guayaquil a fines del periodo colonial). Gõteborg: Instituto Iberoamericano de la Universidad de Gõteborg, 2001.

Contreras Cruces, Hugo. «Las milicias de pardos y morenos libres de Santiago de Chile en el siglo XVIII, 1760-1800». Cuadernos de Historia, vol. 25, 2006, pp. 93-117.

Contreras Cruces, Hugo. «Artesanos mulatos y soldados beneméritos. El Batallón de Infantes de la Patria en la Guerra de Independencia de Chile. 1795-1820». Historia, vol. 1, n. ${ }^{\circ} 44,2011$, pp. 51-89.

Contreras Cruces, Hugo. «Ser leales y parecer «decentes». Milicias de castas e inserción social de los afrodescendientes. Chile, 1675-1760». Tiempo Histórico, vol. 8, n. ${ }^{\circ} 14,2017$, pp. 129-155.

Coria, Luis A. «Los negros en Mendoza. Matrimonios y algo más». Revista de la Junta de Estudios Históricos de Mendoza, vol. 5, 2006, pp. 49-69.

Crespi, Liliana. «Esclavos, libres y libertos del Río de la Plata. Un lento acceso a la ciudadanía». La Ruta del Esclavo en el Río de la Plata. Aportes para el diálogo intercultural. comp. Marisa Pineau. Buenos Aires: Untref, 2011, pp. 187-202. 
De la Fuente, Ariel. Los hijos de Facundo. Caudillos y montoneras en la provincia de la Rioja durante el proceso de formación del Estado nacional argentino (18531870). Buenos Aires: Prometeo, 2014.

Di Meglio, Gabriel. «Las palabras de Manul. La plebe porteña y la política en los años revolucionarios». ¿Y el pueblo dónde está?. Contribuciones para una historia popular de la Revolución de Independencia en el Río de la Plata. ed. Raúl O. Fradkin. Buenos Aires: Prometeo, 2009, pp. 107-150.

Donoso Ríos, Ana Laura. «Anhelos de libertad. Familias afromestizas en San juan de la Frontera (Argentina 1750-1800)». Historia y Memoria, vol. 12, 2016, pp. 85119.

Fradkin, Raúl O. ¿Y el pueblo dónde está?. Contribuciones para una historia popular de la Revolución de Independencia en el Río de la Plata. Buenos Aires: Prometeo, 2009.

Fradkin, Raúl O. y Gabriel Di Meglio. Hacer política. La participación popular en el siglo XIX rioplatense. Buenos Aires: Prometeo, 2013.

Fraga, Ana. «Caminos de libertad en tiempos de revolución. Los esclavos en la Provincia Oriental Artiguista, 1815-1820». Estudios sobre la cultura afrorioplatense. Historia y presente. comp., Arturo Bentancur, Alex Borucki y Ana Fraga. Montevideo: FHCE, Universidad de la República, 2004, pp. 45-66.

Goldberg, Marta Beatriz. «Afrosoldados de Buenos Aires en armas para defender a sus amos». "Negros de la patria». Los afrodescendientes en las luchas por la independencia en el antiguo Virreinato del Río de La Plata. eds., Silvia C. Mallo e Ignacio Telesca. Buenos Aires: SB, 2010. 39-63

Gonzalez Arrili, Bernardo. Historia de la Argentina. Según las biografías de sus hombres y mujeres. Buenos Aires: Nobis, 1964.

González Undurraga, Carolina. «Los usos del honor por esclavos y esclavas: del cuerpo injuriado al cuerpo liberado (Chile, 1750-1823)». Nuevo Mundo Mundos Nuevos [en línea], Colloques. Recuperado a partir de: http://journals.openedition.org/nuevomundo/2869

Grubessich, Arturo S. «Esclavitud en Chile durante el siglo XVIII: el matrimonio como una forma de integración social». Revista de Historia, vol. 2, 1992, pp. 115-128.

Guzmán, Florencia. «De esclavizados a afrodescendientes. Un análisis histórico sobre la movilidad social a finales de la colonia». Boletín Americanista, año LXI, vol. 2, n. ${ }^{\circ}$ 63, 2011, pp. 13-34.

Guzmán. Florencia. «Afroargentinos, guerra y política, durante las primeras décadas del siglo XIX. Una aproximación hacia una historia social de la revolución». Estudios Históricos, vol. 11, 2013, pp. 1-24.

Hudson, Damián. Recuerdos históricos sobre la provincia de Cuyo. Tomo 1. Mendoza: Ediunc, 2008.

Mallo, Silvia. «La libertad en el discurso del Estado, de amos y esclavos, 1780-1830». Revista de Historia de América, vol. 112, 1991, pp. 121-146.

Mallo, Silvia C., e Ignacio Telesca. «Negros de la patria». Los afrodescendientes en las luchas por la independencia en el antiguo Virreinato del Río de La Plata. Buenos Aires: SB, 2010. 
Masini Calderón, José Luis. Régimen jurídico de la esclavitud negra en Hispanoamérica hasta 1810. Mendoza: D’Accurzio, 1958.

Masini Calderón, José Luis. «La esclavitud negra en la República Argentina». Revista de la Junta de Estudios Históricos de Mendoza, Segunda Época, vol. 1, 1961, pp. 135-161.

Masini Calderón, José Luis. La esclavitud negra en Mendoza. Época Independiente. Mendoza: D’Accurzio, 1962.

Masini Calderón, José Luis. «La esclavitud negra en San Juan y San Luis. Época independiente». Revista de Historia Americana y Argentina, vols. 7/8, 19621963, pp. 177-210.

Mitre, Bartolomé. Historia de Belgrano y la independencia argentina. Buenos Aires: Ediciones Anaconda, 1950.

Molina, Hebe y Fabiana Varela. «La vida social y cultural mendocina en el siglo XIX». Panorama de las letras y la cultura en Mendoza. dir., Marta Elena Castellino. Mendoza: Universidad Nacional de Cuyo, 2013, pp. 297-316.

Morales, Orlando Gabriel. «Identificaciones de los plebeyos de color militarizados durante la revolución de la independencia en el Río de la Plata. Cuyo 18101816». Estudios Sociales, n. ${ }^{\circ}$ 53, 2017, pp. 127-154.

Morales, Orlando Gabriel y Luis César Caballero. «Movilidad social de afromestizos movilizados por la independencia y las guerras civiles en el Río de la Plata. Lorenzo Barcala (1795-1835)». Historia y Memoria, vol. 16, 2018, pp. 106-107.

Morales, Orlando Gabriel y Luis César Caballero. «Lorenzo Barcala: "Esclavo”, "hijo de la revolución" y "civilizador de masas" Una discusión de las mitificaciones historiográficas de los afroargentinos». Tiempo Histórico, vol. 9, n. ${ }^{0}$ 16, 2018, pp. 39-59.

Morales, Orlando Gabriel y Luis César Caballero. «Integración social de afromestizos en Cuyo. Trayectoria del capitán José María Molina (Mendoza, 1803-1863)». Estudios afrolatinoamericanos 4: Actas de las sextas jornadas del GEALA. Comps., Eva Lamborghini, María de Lourdes Ghidoli, Juan Francisco Martinez Peria. Buenos Aires: Ediciones del CCC Centro Cultural de la Cooperación Floreal Gorini, 2019, pp. 317-327.

Goldberg, Marta Beatriz. «Afrosoldados de Buenos Aires en armas para defender a sus amos». "Negros de la patria». Los afrodescendientes en las luchas por la independencia en el antiguo Virreinato del Río de La Plata. eds., Silvia C. Mallo e Ignacio Telesca. Buenos Aires: SB, 2010. 39-63

Múnera, Alfonso. El fracaso de la nación. Región, clase y raza en el Caribe colombiano (1717-1821). Bogotá: Banco de la República-El Áncora, 1998.

Rosal, Miguel Ángel. Africanos y afrodescendientes en el Río de La Plata. Siglos XVIIIXIX. Buenos Aires: Dunken, 2009.

Twinam, Ann. «Repensando las reformas sociales de los borbones en las colonias, siglo XVIII». El Taller de la Historia, vol. 5, n. ${ }^{\circ}$ 5, 2013, pp. 5-32.

Peña y Lillo, Silvestre. Gobernadores de Mendoza. El Gobernador Don Pedro Molina. Mendoza: Best, 1937. 
Perrá, Margarita et. al. Archivo del Brigadier General José Nazario Benavidez. Tomo II (1836-1841). San Juan: Universidad Nacional de San Juan, 2007.

Vinson III, Ben. «Los milicianos Pardos y la construcción de la raza en el México colonia». Signos históricos, vol. 2, n. ${ }^{\circ}$ 4, 2000, pp. 87-106. 